\title{
The role of the FOXP family of transcription factors in ASD
}

\author{
J. Michael Bowers and Genevieve Konopka* \\ Department of Neuroscience, UT Southwestern Medical Center, Dallas, TX, USA
}

\begin{abstract}
Autism spectrum disorders (ASD) is a neurodevelopmental disease with complex genetics; however, the genes that are responsible for this disease still remain mostly unknown. Here, we focus on the FOXP family of transcription factors as there is emerging evidence strongly linking these genes to ASD and other genes implicated in ASD. The FOXP family of genes includes three genes expressed in the central nervous system: FOXP1, FOPX2, and FOXP4. This unique group of transcription factors has known functions in brain development as well as the evolution of language. We will also discuss the other genes including transcriptional targets of FOXP genes that have been found to be associated with language and may be important in the pathophysiology of ASD. Finally, we will review the emerging animal models currently being used to study the function of the FOXP genes within the context of ASD symptomology. The combination of gene expression and animal behavior is critical for elucidating how genes such as the FOXP family members are key players within the framework of the developing brain.
\end{abstract}

Keywords: FOXP2, FOXP1, autism, genetics

\section{Introduction}

Autism is characterized by impaired language communication, qualitative impairment in social interactions, as well as restricted repetitive and stereotyped behaviors/interests [1]. The prevalence rate of autism in the general population is estimated to be $1 \%[2,3]$. Moreover, there is a strong sex bias in the prevalence rates with ratios of $4: 1$, favoring males over females [ 4 , 5]. A broader range of associated symptoms is also recognized, termed autism spectrum disorders (ASD). The heritability of ASD has been estimated to be $90 \%$; making ASD the most heritable of the childhood onset neuropsychiatric disorders [6,7]. Autism is comorbid with a number of other diseases, including Rett, Fragile X, and Angelman Syndrome [8]. Numerous studies have searched for causal genetic factors for ASD, and the results point to a complex genetic architecture converging on signaling pathways involved in the devel-

\footnotetext{
* Corresponding author: Genevieve Konopka, Department of Neuroscience, University of Texas Southwestern Medical Center, 5323 Harry Hines Blvd., ND4.300, Dallas, TX 75390-9111, USA. Tel.: +1 214648 5135; E-mail: Genevieve.Konopka@utsouthwestern.edu.
}

opment of the nervous system $[9,10]$ that are also likely interacting with environmental and epigenetic phenomenon. The focus of this review will be to discuss the most recent genetic findings for ASD within the context of a family of transcription factors linked to language, brain development, and ASD.

\section{The genetics of language}

Identifying the genes involved in language is not only important for the understanding of disorders such as ASD, but it also provides a window into understanding the evolution of the human brain since spoken language is only present in humans. While other animals have developed methods of vocal communication, none have the ability to convey recursive ideas (i.e. ideas embedded within other ideas), although the idea of humanspecific recursion is still being debated [11-14].

Similar to ASD, Specific Language Impairment (SLI) is a common developmental disorder with estimates of prevalence around $7 \%$ for school-aged children [15]. Moreover, twin studies have pointed to a genetic etiology for SLI with a complex genetic archi- 
tecture [16]. Patients with SLI are not cognitively impaired or socially withdrawn as in ASD, but they do have impairments in communication [17]. The gene encoding contactin associated protein-like 2 (CNTNAP2) has been associated with a specific endophenotype related to a core feature of SLI, nonword repetition defects [18]. CNTNAP2 is a member of the neurexin superfamily of proteins important in the development of cell adhesion and synaptic connections in the brain [19]. Both rare and common variations in CNTNAP2 have been identified in patients with ASD [20-24]. Analysis of one patient cohort revealed an association between CNTNAP2 variants and the age of the first spoken word, a language endophenotype [20]. Another group of patients with ASD and speech delay had multiple structural variations containing CNTNAP2 [23]. CNTNAP2 has been shown to have an enriched expression in the human frontal pole $[20,25]$. In contrast, expression of CNTNAP2 in lower organisms is not focally enriched in any region of the cortex [25]. Furthermore, CNTNAP2 knockout mice have decreased ultrasonic vocalizations [26]. These data support an important function for CNTNAP2 in cognition and language. Two additional SLI candidate genes have shown strong association to the disorder: the calcium-transporting ATPase 2C2 (ATP2C2) and c-MAF inducing protein (CMIP) genes [27]. However, neither of these genes has been linked to ASD. Thus, while there may be some convergence of ASD with other language disorders, the complex genetics of all of these disorders makes deciphering the signaling pathways even more challenging.

\section{FOXP2}

A key insight into identifying genes involved in language has come from investigations focusing on atypical phenotypic expression. Such investigations led to the discovery of a large multigenerational family known as the KE family, in which affected family members exhibit verbal dyspraxia, or deficits in coordinating the complex oral-facial motor movements associated with spoken language [28]. Moreover, affected individuals from the KE family also have below average IQ and syntactic impairments (i.e., an inability to use the proper rules associated with grammar) $[28,29]$. It was the cytogenetic investigation of this family plus an unrelated affected individual that uncovered the forkhead box $\mathrm{P} 2$ or FOXP2 gene on chromosome 7 [30,31].

FOXP2 is a member of the forkhead family of transcription factors, and is highly homologous to two other forkhead transcription factors, FOXP1 and FOXP4 [32]. All three FOXP family members have several conserved domains: a polyglutamine tract, a zinc finger domain, a leucine zipper, and a forkhead DNA binding domain (Fig. 1A-C). Further analysis of the affected members of the KE family revealed a point mutation in the DNA binding domain of FOXP2 resulting in an amino acid change of arginine to histidine (R553H) [31]. Subsequent analysis of this particular mutation revealed that it disrupts the ability of FOXP2 to bind to DNA [33]. Affected individuals are heterozygous for this mutation, leading to the hypothesis that the mutant form of FOXP2 may act like a dominant negative, relocating the wildtype FOXP2 protein to outside of the nucleus where it can no longer act as a transcriptional regulator [33,34]. This type of interaction makes sense in light of evidence showing FOXP family members can either homodimerize (e.g. FOXP2-FOXP2) or heterodimerize (e.g. FOXP2-FOXP1) through their zinc finger domains [32]. In addition to the KE family, several other studies have described patients with mutations or truncations in FOXP2 displaying a similar verbal dyspraxia [35-40]. Together, these reports have firmly established the role of FOXP2 in language.

The expression of FOXP2 is not limited to the central nervous system; it is also expressed in the lungs, kidney, intestine, spleen, and skeletal muscle [41]. However, for the purpose of describing how FOXP2 is involved in ASD, we will limit our discussion to its expression in the brain. In humans, FOXP2 is highly expressed during mid-gestation (Fig. 2A) [42,43]. This is a critical time point in brain development during which neural specification is occurring and extensive configuration of the brain is taking place. Furthermore, the expression pattern of FOXP2 in humans declines postnatally and continues to decline to nearly undetectable levels in the adult human brain (Fig. 2A).

In contrast to the expression pattern of FOXP2 in humans, FoxP2 expression in both rodent and zebra finch brains remains at high levels from the embryonic period thru adulthood [42,44]. This dissimilarity in expression differences may point to a unique function of FOXP2 in the developing human brain, and relate to its role in a human-specific trait such as language. In humans, FOXP2 is primarily limited to expression in the striatum, specific thalamic nuclei, hippocampus, cerebellum, and layer six of the cortex $[42,45,46]$. Expression of FOXP2 in these regions of the brain, in particular the cortical-striatal expression, points to a potential role for FOXP2 in many neuropsychiatric disorders.

Studies examining genetic association between polymorphisms in FOXP2 and autism have been inconclu- 
FOXP2
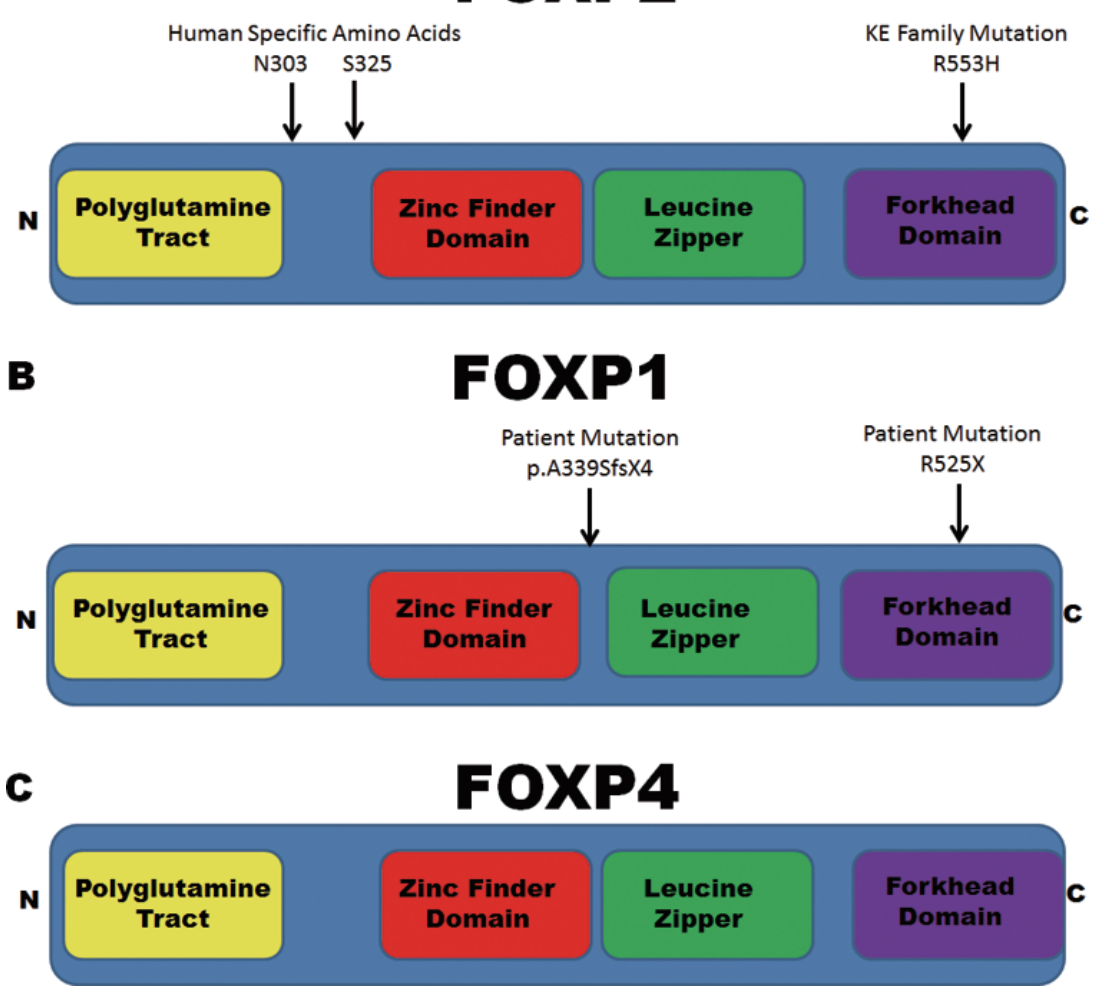

Fig. 1. Conserved domains of the FOXP family members. A) Schematic of FOPX2 showing the polyglutamine tract, a zinc finger domain, a leucine zipper, and a forkhead DNA binding domain including the mutation causing the disruption of FOXP2 in the KE family. B) Schematic of the FOXP1 mutation deletion in patient \# 12817 from (O'Roak et al., 2011) and patient A from (Hamden et al., 2010) as well as the same functional domains. C) Schematic of FOXP4 highlighting its similarity with the other two brain expressed FOXP family members. (Colours are visible in the online version of the article; http://dx.doi.org/10.3233/DMA-2012-0919)

sive. A number of initial studies reported no associations between polymorphisms in FOXP2 and ASD [4749]. Moreover, whole genome microarrays of ASD samples have not found an association of FOXP2 with the disorder [50-56]. In contrast, at least four studies have uncovered polymorphisms in FOXP2 associated with ASD [57-60], and potential imprinting of FOXP2 has been uncovered in a group of patients with ASD [35]. Taken together these studies suggest the potential for direct disruptions to FOXP2 leading to ASD. Nevertheless, these and many other studies are limited by sample size and fixed marker sets for genotyping. Future studies encompassing whole genome sequencing in large patient populations should more reliably address the direct role of FOXP2 in ASD.

An alternative explanation for many of the contradictory findings correlating FOXP2 variation with ASD may be due to the complex splicing of FOXP2. At least eight isoforms of FOXP2 have been identified as well as almost a dozen additional splice isoforms (UCSC hu- man genome browser hg19) [61,62]. Moreover, it has been suggested, based on Northern blot analysis that an isoform twice as large as any of the reported FOXP2 isoforms may exist [62]. Nevertheless, stronger support for a role for FOXP2 in ASD can be found in the downstream signaling pathways regulated by FOXP2.

While the misregulation of the target genes controlled by FOXP2 is not fully characterized, several studies have uncovered FOXP2 regulation of ASD genes. Through the use of chromatin immunoprecipitation coupled to microarrays, a comparison of FOXP2 ChIP-chip targets in brain with a list of ASD candidate genes yields a number of overlapping genes [9,10,63]. This overlap includes: A2BP1, DISC1, DPP6, ITGB3, MTF1, RPL10, RPS6KA2, and TDO2 (Table 1). In addition, an overlap of the differentially expressed genes regulated by human or chimpanzee FOXP2 with ASD genes also includes: GRM8, DPYD, IGFPB3, MAOB, and VIP [64]. Other, more directed, studies have detailed FOXP2 regulation of autism candidate genes, in particular CNTNAP2 [18] and MET [65]. 
A

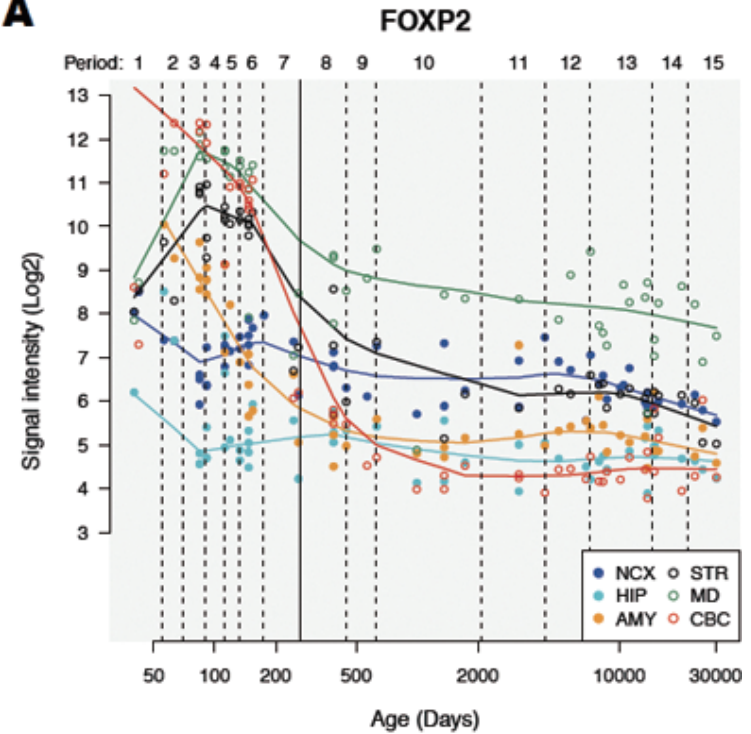

B

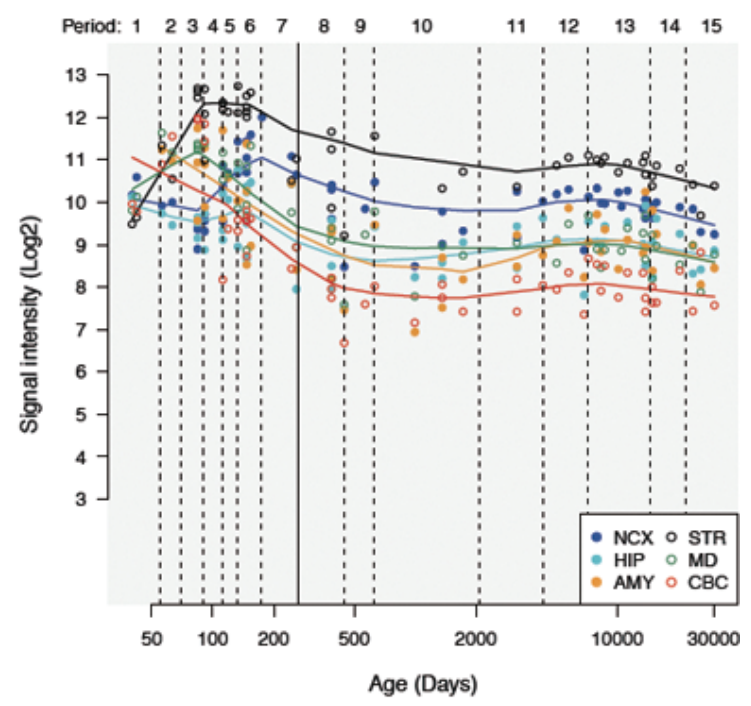

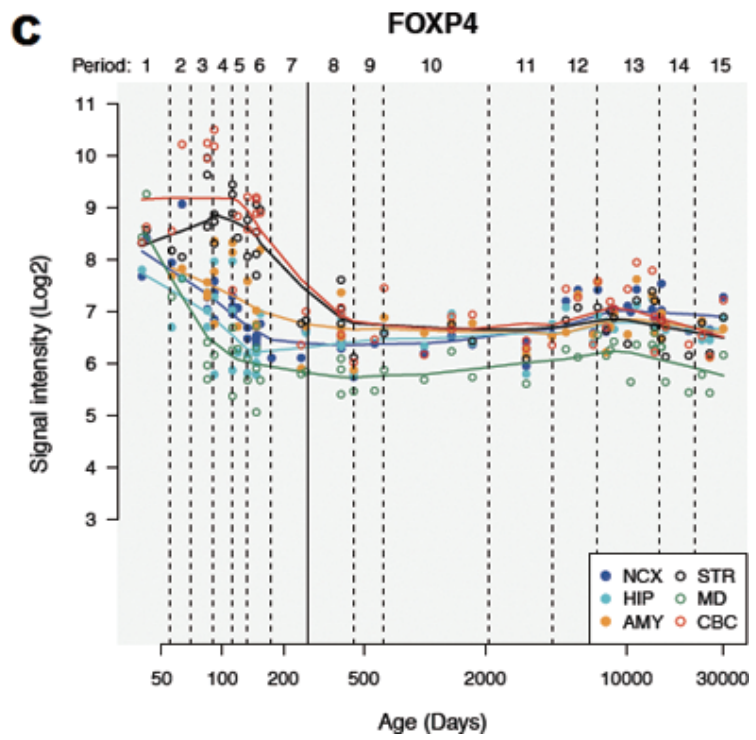

Fig. 2. Expression of FOXP family members in the developing human brain. Expression of A) FOXP2, B) FOXP1, and C) FOXP4 throughout human brain development. The solid line indicates birth. NCX = neocortex, HIP = hippocampus, AMY $=$ amygdala, STR $=$ striatum, MD $=$ mediodorsal nucleus of the thalamus, and $\mathrm{CBC}=$ cerebellum. Data are derived from Kang et al. using the Human Brain Transcriptome database (http://hbatlas.org/). (Colours are visible in the online version of the article; http://dx.doi.org/10.3233/DMA-2012-0919)

In situ hybridization of both FOXP2 and CNTNAP2 in the developing human brain shows an inverse pattern of mRNA expression [18]. Moreover, forced expression of FOXP2 in human neuronal cells leads to a concomitant reduction of CNTNAP2 [18]. Recent findings show FOXP2 is able to bind to the CNTNAP2 gene in human neuronal cells [18], and in one individual with ASD and CNTNAP2 variation, the FOXP2 binding site were deleted [23]. Collectively, these data suggest that
FOXP2 directly represses CNTNAP2 expression. This regulation may be critical for human language and consequently be aberrant in both ASD and SLI.

The gene encoding MET proto-oncogene has been strongly associated with ASD [51,66-68]. In particular, a polymorphism in the promoter of $M E T$ is associated with ASD, and results in reduced transcription of $M E T$ in cell lines [69]. Furthermore, MET expression is reduced in the temporal cortex of patients with this par- 
ticular mutation [70]. The expression pattern of MET in the developing human brain is quite striking; it is primarily expressed in the cortex and it is enriched in the developing temporal lobe [65]. This pattern suggests a potential role in pathways important for language. While several studies have characterized the expression pattern and function of Met in the mouse [71-74], there is little known about the regulation of human MET. Due to the enrichment of MET in the temporal lobe and the previous identification of other ASD genes downstream of FOXP2, the hypothesis of whether MET might also be regulated by FOXP2 was tested. Examination of $M E T$ and FOXP2 in the developing human fetal brain revealed inversely correlated expression patterns [65]. Forced expression of FOXP2 in human fetal neural progenitor cells resulted in a concomitant reduction of both MET mRNA and protein. Lastly, electrophoretic mobility shift assays (EMSAs) and ChIP demonstrated direct binding of FOXP2 to the MET promoter. Together, these results confirm that FOXP2 directly binds to the $M E T$ gene and downregulates its expression in differentiating human neurons [65]. Interestingly, FOXP2 is also expressed in the GI tract [41]. It is possible that dysregulation of MET by FOXP2 in the GI tract contributes to the GI manifestations experienced by a subset of ASD patients.

\section{FOXP1 and FOXP4}

In the developing brain, the expression patterns of FoxP1 and FoxP4 have both distinct and overlapping patterns of expression with FoxP2 (Fig. 2B-C) [42,44, 75-77]. In the cortex, FoxP2 is found primarily in the deepest layer of the cortex, layer 6, whereas FoxP1 is found in layers 2-5. In contrast, FoxP4 expression has been found throughout all layers of the cortex $[42,44$, 76-78]. Furthermore, FoxP1, is expressed in both the striatum and thalamus, analogous to FoxP2, although unlike FoxP2, FoxP1 expression is low in the human cerebellum (Fig. 2B) and absent in the rodent cerebellum [44]. In contrast, FoxP4 is present in the cerebellum and hypothesized to be important for dendritic arborization of Purkinje cells [79]. FoxP4 is also expressed in the striatum but its expression declines from a late embryonic to early postnatal stage $[76,80]$. In human brain, only the cerebellum and striatum have high expression of FOXP4 (Fig. 2C). In the early postnatal hippocampus, FoxP4 expression is found in the hilar region and from CA3 to CA1 $[44,76,77]$. In contrast, FoxP1 is expressed mainly in CA1 with no FoxP2
Table 1

Targets of FOXP2 implicated in ASD

\begin{tabular}{|c|c|}
\hline Gene & Reference \\
\hline$A 2 B P 1$ & 4,6 \\
\hline CADPS2 & 1 \\
\hline $\mathrm{CDH} 8$ & 6 \\
\hline CNTNAP2 & 5 \\
\hline DISC1 & 4 \\
\hline DPP6 & 4 \\
\hline$D P Y D$ & 2 \\
\hline FRMPD4 & 6 \\
\hline GNAS & 6 \\
\hline GRM 8 & 2 \\
\hline$I G F B P 3$ & 2 \\
\hline ITGB3 & 4 \\
\hline$M A O B$ & 2 \\
\hline $\mathrm{MCPH1}$ & 6 \\
\hline$M E T$ & 3 \\
\hline$M T F 1$ & 4 \\
\hline NTRK3 & 6 \\
\hline RPL10 & 4 \\
\hline RPS6KA2 & 4 \\
\hline SYN1 & 6 \\
\hline TDO2 & 4 \\
\hline$U B E 3 A$ & 6 \\
\hline$V I P$ & 2 \\
\hline \multicolumn{2}{|l|}{$\begin{array}{l}\text { ASD genes are from the SFARI gene database } \\
\text { (https://gene.sfari.org/) }\end{array}$} \\
\hline Enard et al. (2009). Cell & 1 \\
\hline Konopka et al. (2009). Nature & 2 \\
\hline Mukamel et al. (2011). J. Neurosci & 3 \\
\hline Spiteri et al. (2007). Amer J. of Human Genetics & 4 \\
\hline Vernes et al. (2008). N Engl J Med & 5 \\
\hline Vernes et al. (2011). PLoS Genet & 6 \\
\hline
\end{tabular}

expression in the hippocampus throughout development $[44,76,77]$. Interestingly, while the expression of human FOXP2 is low in the hippocampus (Fig. 2A), rodents may have no expression [44,77]. These expression patterns are critical, as not only can FoxP1 and FoxP4 homodimerize similar to FoxP2, but they can also heterodimerize with FoxP2 and each other [32].

A direct relationship between FOXP1 and ASD has been recently uncovered. Several studies have found mutations, deletions, or copy number variations of FOXP1 in individuals with ASD [81-84]. Individuals with variation in FOXPl are reported to have: 1) language acquisition delays with the onset of the first word being 3.5 years of age $[83,84], 2$ ) a working vocabulary of less than 100 words by seven years of age [83], as well as 3) a below average IQ [82,83]. Furthermore, MRI scans from the brains of these individuals' show abnormally enlarged ventricles and also muscle tissue deformities [82]. Moreover, FOXP1 can also repress expression of CNTNAP2 suggesting coordinated transcriptional regulation of ASD genes by FOXP family members [84]. Together, these data suggest that coor- 
dinated downstream signaling of FOXP1 and FOXP2 may be important for language and the signaling pathways involved in ASD.

\section{Animal models of FOXP genes}

Animal models have become an important component of studying the pathophysiology of neurodevelopmental diseases such as ASD [85]. Because of the complex genetic heterogeneity and environmental interactions that contribute to ASD, well-defined animal models that can display core symptoms of the disorder are crucial for research into causes and treatments. Rodents make excellent models for ASD due to their complex behavioral repertoire, which includes: vocal communication, sociability, and intelligence [86-88]. There are numerous mutant mice strains used in ASD research (for a review see [89-92]) including Foxp2 and some of its target genes. In addition, FoxP2 expression and function has also been examined in the songbird [42,93].

Due to the role of FOXP2 in language, a number of studies have investigated the role of Foxp 2 in rodent vocalizations. The most widely used method for eliciting vocalizations in young rodents is through maternal separation in which infant rodent pups emit ultrasonic vocalizations (USVs) in response to separation from their mother [94-96]. Mice with mutations similar to that of the KE family point mutation $[97,98]$ show motor defects, reduced USVs, reduced long term depression (LTD; a measure for a reduction in synaptic efficiency), abnormalities of the cerebellum, and impairments with auditory-motor association learning [34, 97,98]. Furthermore, it has been shown that Foxp2 is not required for the innate vocalizations in very young pups [99]. These authors posit that the defects in USVs observed later in development are likely due to generalized issues with development and motor function [99]. As the molecules and pathways underlying USVs are unknown, it is still uncertain what the structure, or disruption to the structure of USVs, might mean. There is little evidence to suggest that rodent vocalizations are learned, similar to song in birds or language in humans, although the properties of rodent calls are known to be influenced by variables such as genetic background, age, gender, motivation, and environmental factors [100-104]. Finally, gene expression studies have been carried out in both Foxp2 knockout mice [105] and Foxp2 humanized mice [106], and Foxp 2 genome wide binding studies have also been conducted in mice [105]. A number of ASD genes have been identified as potential Foxp 2 targets in these studies (Table 1). These data are an important first step in elucidating the Foxp2 target genes mediating the phenotypes of these genetically modified animals. Further studies will need to be undertaken to place these target genes within the context of specific behaviors such as USVs or LTD and within the larger framework of ASD biology.

FoxP2 is also expressed in the brains of songbirds and its expression changes during song acquisition in the zebra finch [42,107-109]. This plasticity in FoxP2 expression suggests that this gene actively participates in the signaling cascades involved in vocal learning and/or production. Likewise, reduction of FoxP2 in songbirds leads to a disruption of learned song specifically in the precision and quality of the song [110]. Additional work has demonstrated FoxP2 reduction also leads to a decrease in spine density in an area of the zebra finch brain that has a comparable function to the mammalian striatum [111]. This result mirrors what is seen in the striatum of mice heterozygous for Foxp2 [98,106]. These studies also demonstrate that FoxP2 may be playing a role in the learning and/or the shaping of the overall complexity of vocalizations.

The results from both rodent and songbird research highlight the importance of FoxP2 in learned motor skills and place an emphasis on the role of FOXP2 in the more complex aspects of speech and language rather than simply a motor function. These data also support the use of FoxP2 animal model systems for the study of brain development and targeted therapeutics in ASD. In addition, there is also evidence suggesting that Foxp1 may also be involved in CNS organization of motor behavior. A recent study has found that mice with a conditional knockout of Foxpl in motor neurons have profound impairments in limb coordination during motor behaviors [112]. The functions and targets of Foxp1 or Foxp4 in the developing mammalian brain have yet to be determined.

\section{Future directions}

Examination of FOXP2 in multiple systems is uncovering the downstream functions of this gene that may be important for ASD including target genes, cellular phenotypes, and modulation of animal behavior. These studies are critical for placing the FOXP2 target genes into context within the framework of the developing brain. Moreover, it will be important to more 
fully understand the role of both FOXP1 and FOXP4, as well as their target genes, in the nervous system. Developing a complete appreciation for the function of FOXP-regulated signaling pathways in ASD will require integration of genetic, developmental, molecular, and behavioral research. This will provide a more complete picture of FOXP function in ASD and assist in elucidating potential targets for therapeutic interventions.

\section{Acknowledgements}

GK is a Jon Heighten Scholar in Autism Research. GK and JMB are also supported by the NIMH (R00 MH090238 and F32MH086258).

\section{References}

[1] APA. Diagnostic and Statistical Manual of Mental Disorders DSM-IV-TR Fourth Edition (Text Revision) Washington DC, USA, 2000.

[2] Baird G, Simonoff E, Pickles A, et al. Prevalence of disorders of the autism spectrum in a population cohort of children in South Thames: the Special Needs and Autism Project (SNAP). Lancet. 2006; 368: 210-215.

[3] Szatmari P, Paterson AD, Zwaigenbaum L, et al. Mapping autism risk loci using genetic linkage and chromosomal rearrangements. Nature genetics. 2007; 39: 319-328.

[4] Chakrabarti S, Fombonne E. Pervasive developmental disorders in preschool children. JAMA: the Journal of the American Medical Association. 2001; 285: 3093-3099.

[5] Fombonne E. Epidemiology of autistic disorder and other pervasive developmental disorders. The Journal of clinical psychiatry. 2005; 66(Suppl 10): 3-8.

[6] Sousa I HR, Pagnamenta A, Monaco M. Unravelling the Genetics of Autism Spectrum Disorders. Cambridge University Press, Cambridge: MA, 2011.

[7] Bailey A, Le Couteur A, Gottesman I, et al. Autism as a strongly genetic disorder: evidence from a British twin study. Psychological medicine. 1995; 25: 63-77.

[8] Warren Z, McPheeters ML, Sathe N, Foss-Feig JH, Glasser A, Veenstra-Vanderweele J. A systematic review of early intensive intervention for autism spectrum disorders. Pediatrics. 2011; 127: e1303-1311.

[9] Abrahams BS, Geschwind DH. Advances in autism genetics: on the threshold of a new neurobiology. Nat Rev Genet. 2008; 9: 341-355.

[10] Bill BR, Geschwind DH. Genetic advances in autism: Heterogeneity and convergence on shared pathways. Curr Opin Genet Dev. 2009; 19: 271-278.

[11] Premack D. Human and animal cognition: continuity and discontinuity. Proc Natl Acad Sci U S A. 2007; 104: 1386113867.

[12] Penn DC, Holyoak KJ, Povinelli DJ. Darwin's mistake: explaining the discontinuity between human and nonhuman minds. Behav Brain Sci. 2008; 31: 109-130; discussion 130178.
[13] Pinker S, Jackendoff R. The faculty of language: What's special about it? Cognition. 2005; 95: 201-236.

[14] Hauser MD, Chomsky N, Fitch WT. The faculty of language: what is it, who has it, and how did it evolve? Science. 2002; 298: $1569-1579$.

[15] Tomblin JB, Records NL, Buckwalter P, Zhang X, Smith E, O'Brien M. Prevalence of specific language impairment in kindergarten children. J Speech Lang Hear Res. 1997; 40: 1245-1260.

[16] Bishop DV. The role of genes in the etiology of specific language impairment. J Commun Disord. 2002; 35: 311-328.

[17] Bishop DV. What Causes Specific Language Impairment in Children? Current directions in psychological science. 2006; 15: $217-221$.

[18] Vernes SC, Newbury DF, Abrahams BS, et al. A functional genetic link between distinct developmental language disorders. The New England journal of medicine. 2008; 359: 2337-2345.

[19] Poliak S, Gollan L, Martinez R, et al. Caspr2, a new member of the neurexin superfamily, is localized at the juxtaparanodes of myelinated axons and associates with $\mathrm{K}+$ channels. Neuron. 1999; 24: 1037-1047.

[20] Alarcon M, Abrahams BS, Stone JL, et al. Linkage, association, and gene-expression analyses identify CNTNAP2 as an autism-susceptibility gene. Am J Hum Genet. 2008; 82: 150-159.

[21] Arking DE, Cutler DJ, Brune CW, et al. A common genetic variant in the neurexin superfamily member CNTNAP2 increases familial risk of autism. Am J Hum Genet. 2008; 82: 160-164.

[22] Bakkaloglu B, O'Roak BJ, Louvi A, et al. Molecular cytogenetic analysis and resequencing of contactin associated protein-like 2 in autism spectrum disorders. Am J Hum Genet. 2008; 82: 165-173.

[23] Poot M, Beyer V, Schwaab I, et al. Disruption of CNTNAP2 and additional structural genome changes in a boy with speech delay and autism spectrum disorder. Neurogenetics. 2010; 11: 81-89.

[24] Li X, Hu Z, He Y, et al. Association analysis of CNTNAP2 polymorphisms with autism in the Chinese Han population. Psychiatr Genet. 2010; 20: 113-117.

[25] Abrahams BS, Tentler D, Perederiy JV, Oldham MC, Coppola G, Geschwind DH. Genome-wide analyses of human perisylvian cerebral cortical patterning. Proc Natl Acad Sci U S A. 2007; 104: 17849-17854.

[26] Penagarikano O, Abrahams BS, Herman EI, et al. Absence of CNTNAP2 leads to epilepsy, neuronal migration abnormalities, and core autism-related deficits. Cell. 2011; 147: 235-246.

[27] Newbury DF, Fisher SE, Monaco AP. Recent advances in the genetics of language impairment. Genome medicine. 2010; 2: 6 .

[28] Vargha-Khadem F, Watkins K, Alcock K, Fletcher P, Passingham R. Praxic and nonverbal cognitive deficits in a large family with a genetically transmitted speech and language disorder. Proc Natl Acad Sci U S A. 1995; 92: 930-933.

[29] Watkins KE, Dronkers NF, Vargha-Khadem F. Behavioural analysis of an inherited speech and language disorder: comparison with acquired aphasia. Brain. 2002; 125: 452-464.

[30] Lai CS, Fisher SE, Hurst JA, et al. The SPCH1 region on human 7q31: genomic characterization of the critical interval and localization of translocations associated with speech and language disorder. Am J Hum Genet. 2000; 67: 357-368. 
[31] Lai CS, Fisher SE, Hurst JA, Vargha-Khadem F, Monaco AP. A forkhead-domain gene is mutated in a severe speech and language disorder. Nature. 2001; 413: 519-523.

[32] Li S, Weidenfeld J, Morrisey EE. Transcriptional and DNA binding activity of the Foxp1/2/4 family is modulated by heterotypic and homotypic protein interactions. Molecular and cellular biology. 2004; 24: 809-822.

[33] Vernes SC, Nicod J, Elahi FM, et al. Functional genetic analysis of mutations implicated in a human speech and language disorder. Hum Mol Genet. 2006; 15: 3154-3167.

[34] Kurt S, Fisher SE, Ehret G. Foxp2 mutations impair auditorymotor association learning. PloS one. 2012; 7: e33130.

[35] Feuk L, Kalervo A, Lipsanen-Nyman M, et al. Absence of a paternally inherited FOXP2 gene in developmental verbal dyspraxia. Am J Hum Genet. 2006; 79: 965-972.

[36] Lennon PA, Cooper ML, Peiffer DA, et al. Deletion of 7q31.1 supports involvement of FOXP2 in language impairment: clinical report and review. Am J Med Genet A. 2007; 143A: 791-798.

[37] MacDermot KD, Bonora E, Sykes N, et al. Identification of FOXP2 truncation as a novel cause of developmental speech and language deficits. Am J Hum Genet. 2005; 76: 10741080 .

[38] Shriberg LD, Ballard KJ, Tomblin JB, Duffy JR, Odell KH, Williams CA. Speech, prosody, and voice characteristics of a mother and daughter with a 7;13 translocation affecting FOXP2. J Speech Lang Hear Res. 2006; 49: 500-525.

[39] Zeesman S, Nowaczyk MJ, Teshima I, et al. Speech and language impairment and oromotor dyspraxia due to deletion of 7q31 that involves FOXP2. Am J Med Genet A. 2006; 140: 509-514.

[40] Pinel P, Fauchereau F, Moreno A, et al. Genetic variants of FOXP2 and KIAA0319/TTRAP/THEM2 locus are associated with altered brain activation in distinct language-related regions. The Journal of neuroscience: The official journal of the Society for Neuroscience. 2012; 32: 817-825.

[41] Shu W, Yang H, Zhang L, Lu MM, Morrisey EE. Characterization of a new subfamily of winged-helix/forkhead (Fox) genes that are expressed in the lung and act as transcriptional repressors. J Biol Chem. 2001; 276: 27488-27497.

[42] Teramitsu I, Kudo LC, London SE, Geschwind DH, White SA. Parallel FoxP1 and FoxP2 expression in songbird and human brain predicts functional interaction. The Journal of neuroscience: The official journal of the Society for Neuroscience. 2004; 24: 3152-3163.

[43] Kang C, Drayna D. Genetics of speech and language disorders. Annual review of genomics and human genetics. 2011; 12: $145-164$.

[44] Ferland RJ, Cherry TJ, Preware PO, Morrisey EE, Walsh CA. Characterization of Foxp2 and Foxp1 mRNA and protein in the developing and mature brain. The Journal of comparative neurology. 2003; 460: 266-279.

[45] Lai CS, Gerrelli D, Monaco AP, Fisher SE, Copp AJ. FOXP2 expression during brain development coincides with adult sites of pathology in a severe speech and language disorder. Brain. 2003; 126: 2455-2462.

[46] Kang HJ, Kawasawa YI, Cheng F, et al. Spatio-temporal transcriptome of the human brain. Nature. 2011; 478: 483489.

[47] Gauthier J, Joober R, Mottron L, et al. Mutation screening of FOXP2 in individuals diagnosed with autistic disorder. Am J Med Genet A. 2003; 118A: 172-175.

[48] Newbury DF, Bonora E, Lamb JA, et al. FOXP2 is not a major susceptibility gene for autism or specific language impairment. Am J Hum Genet. 2002; 70: 1318-1327.

[49] Wassink TH, Piven J, Vieland VJ, et al. Evaluation of FOXP2 as an autism susceptibility gene. Am J Med Genet. 2002; 114: 566-569.

[50] Kumar RA, KaraMohamed S, Sudi J, et al. Recurrent 16p11.2 microdeletions in autism. Hum Mol Genet. 2008; 17: 628638.

[51] Marshall CR, Noor A, Vincent JB, et al. Structural variation of chromosomes in autism spectrum disorder. Am J Hum Genet. 2008; 82: 477-488.

[52] Weiss LA, Shen Y, Korn JM, et al. Association between microdeletion and microduplication at 16p11.2 and autism. N Engl J Med. 2008; 358: 667-675.

[53] Ma D, Salyakina D, Jaworski JM, et al. A genome-wide association study of autism reveals a common novel risk locus at 5p14.1. Ann Hum Genet. 2009; 73: 263-273.

[54] Wang K, Zhang H, Ma D, et al. Common genetic variants on $5 \mathrm{p} 14.1$ associate with autism spectrum disorders. Nature. 2009; 459: 528-533.

[55] Anney R, Klei L, Pinto D, et al. A genome-wide scan for common alleles affecting risk for autism. Hum Mol Genet. 2010 .

[56] Abrahams BS, Geschwind DH. Connecting genes to brain in the autism spectrum disorders. Arch Neurol. 2010; 67: 395-399.

[57] Gong X, Jia M, Ruan Y, et al. Association between the FOXP2 gene and autistic disorder in Chinese population. Am J Med Genet B Neuropsychiatr Genet. 2004; 127B: 113-116.

[58] Laroche F, Ramoz N, Leroy S, et al. Polymorphisms of coding trinucleotide repeats of homeogenes in neurodevelopmental psychiatric disorders. Psychiatr Genet. 2008; 18: 295-301.

[59] Li H, Yamagata T, Mori M, Momoi MY. Absence of causative mutations and presence of autism-related allele in FOXP2 in Japanese autistic patients. Brain Dev. 2005; 27: 207-210.

[60] Marui T, Koishi S, Funatogawa I, et al. No association of FOXP2 and PTPRZ1 on 7q31 with autism from the Japanese population. Neurosci Res. 2005; 53: 91-94.

[61] Kent WJ, Sugnet CW, Furey TS, et al. The human genome browser at UCSC. Genome Res. 2002; 12: 996-1006.

[62] Bruce HA, Margolis RL. FOXP2: novel exons, splice variants, and CAG repeat length stability. Human genetics. 2002; 111: $136-144$.

[63] Basu SN, Kollu R, Banerjee-Basu S. AutDB: a gene reference resource for autism research. Nucleic Acids Res. 2009; 37: D832-836.

[64] Konopka G, Bomar JM, Winden K, et al. Human-specific transcriptional regulation of CNS development genes by FOXP2. Nature. 2009; 462: 213-217.

[65] Mukamel Z, Konopka G, Wexler E, et al. Regulation of MET by FOXP2, genes implicated in higher cognitive dysfunction and autism risk. The Journal of neuroscience: The official journal of the Society for Neuroscience. 2011; 31: 1143711442.

[66] Campbell DB, Li C, Sutcliffe JS, Persico AM, Levitt P. Genetic evidence implicating multiple genes in the MET receptor tyrosine kinase pathway in autism spectrum disorder. Autism Res. 2008; 1: 159-168.

[67] Sousa I, Clark TG, Toma C, et al. MET and autism susceptibility: family and case-control studies. European Journal of Human Genetics: EJHG. 2009; 17: 749-758.

[68] Jackson PB, Boccuto L, Skinner C, et al. Further evidence that the rs $1858830 \mathrm{C}$ variant in the promoter region of the 
MET gene is associated with autistic disorder. Autism Res. 2009; 2: 232-236

[69] Campbell DB, Sutcliffe JS, Ebert PJ, et al. A genetic variant that disrupts MET transcription is associated with autism. Proc Natl Acad Sci U S A. 2006; 103: 16834-16839.

[70] Campbell DB, D’Oronzio R, Garbett K, et al. Disruption of cerebral cortex MET signaling in autism spectrum disorder. Ann Neurol. 2007; 62: 243-250.

[71] Judson MC, Bergman MY, Campbell DB, Eagleson KL, Levitt P. Dynamic gene and protein expression patterns of the autism-associated met receptor tyrosine kinase in the developing mouse forebrain. J Comp Neurol. 2009; 513: 511-531.

[72] Martins GJ, Plachez C, Powell EM. Loss of embryonic MET signaling alters profiles of hippocampal interneurons. Dev Neurosci. 2007; 29: 143-158.

[73] Sun W, Funakoshi H, Nakamura T. Localization and functional role of hepatocyte growth factor (HGF) and its receptor c-met in the rat developing cerebral cortex. Brain Res Mol Brain Res. 2002; 103: 36-48.

[74] Ohya W, Funakoshi H, Kurosawa T, Nakamura T. Hepatocyte growth factor (HGF) promotes oligodendrocyte progenitor cell proliferation and inhibits its differentiation during postnatal development in the rat. Brain Res. 2007; 1147: 51-65.

[75] Lu MM, Li S, Yang H, Morrisey EE. Foxp4: a novel member of the Foxp subfamily of winged-helix genes co-expressed with Foxp1 and Foxp2 in pulmonary and gut tissues. Gene Expr Patterns. 2002; 2: 223-228.

[76] Takahashi K, Liu FC, Hirokawa K, Takahashi H. Expression of Foxp4 in the developing and adult rat forebrain. Journal of neuroscience research. 2008; 86: 3106-3116.

[77] Takahashi K, Liu FC, Oishi T, et al. Expression of FOXP2 in the developing monkey forebrain: comparison with the expression of the genes FOXP1, PBX3, and MEIS2. The Journal of Comparative Neurology. 2008; 509: 180-189.

[78] Rowell JJ, Mallik AK, Dugas-Ford J, Ragsdale CW. Molecular analysis of neocortical layer structure in the ferret. $J$ Comp Neurol. 2010; 518: 3272-3289.

[79] Tam WY, Leung CK, Tong KK, Kwan KM. Foxp4 is essential in maintenance of Purkinje cell dendritic arborization in the mouse cerebellum. Neuroscience. 2011; 172: 562-571.

[80] Schuller U, Kho AT, Zhao Q, Ma Q, Rowitch DH. Cerebellar 'transcriptome' reveals cell-type and stage-specific expression during postnatal development and tumorigenesis. Molecular and cellular neurosciences. 2006; 33: 247-259.

[81] Hamdan FF, Daoud H, Rochefort D, et al. De novo mutations in FOXP1 in cases with intellectual disability, autism, and language impairment. American journal of human genetics. 2010; 87: 671-678.

[82] Pariani MJ, Spencer A, Graham JM, Jr., Rimoin DL. A 785kb deletion of 3p14.1p13, including the FOXP1 gene, associated with speech delay, contractures, hypertonia and blepharophimosis. European journal of medical genetics. 2009; 52: 123-127.

[83] Horn D, Kapeller J, Rivera-Brugues N, et al. Identification of FOXP1 deletions in three unrelated patients with mental retardation and significant speech and language deficits. Human mutation. 2010; 31: E1851-1860.

[84] O'Roak BJ, Deriziotis P, Lee C, et al. Exome sequencing in sporadic autism spectrum disorders identifies severe de novo mutations. Nature genetics. 2011; 43: 585-589.

[85] Iwata K, Matsuzaki H, Takei N, Manabe T, Mori N. Animal Models of Autism: An Epigenetic and Environmental View- point. Journal of Central Nervous System Disease. 2010; 2: 37.

[86] Crawley JN. Designing mouse behavioral tasks relevant to autistic-like behaviors. Mental retardation and developmental disabilities research reviews. 2004; 10: 248-258.

[87] Whishaw IQ, Metz GA, Kolb B, Pellis SM. Accelerated nervous system development contributes to behavioral efficiency in the laboratory mouse: a behavioral review and theoretical proposal. Developmental psychobiology. 2001; 39: 151-170.

[88] Rosenthal N, Brown S. The mouse ascending: Perspectives for human-disease models. Nature cell biology. 2007; 9: 993999.

[89] Halladay AK, Amaral D, Aschner M, et al. Animal models of autism spectrum disorders: information for neurotoxicologists. Neurotoxicology. 2009; 30: 811-821.

[90] Ey E, Leblond CS, Bourgeron T. Behavioral profiles of mouse models for autism spectrum disorders. Autism Research: Official Journal of the International Society for Autism Research, 2011.

[91] Moy SS, Nadler JJ, Magnuson TR, Crawley JN. Mouse models of autism spectrum disorders: The challenge for behavioral genetics. American journal of medical genetics Part $C$, Seminars in medical genetics. 2006; 142C: 40-51.

[92] McFarlane HG, Kusek GK, Yang M, Phoenix JL, Bolivar VJ, Crawley JN. Autism-like behavioral phenotypes in BTBR $\mathrm{T}+\mathrm{tf} / \mathrm{J}$ mice. Genes, brain, and behavior. 2008; 7: 152-163.

[93] Hilliard AT, Miller JE, Fraley ER, Horvath S, White SA. Molecular microcircuitry underlies functional specification in a basal ganglia circuit dedicated to vocal learning. Neuron. 2012; 73: 537-552.

[94] Branchi I, Santucci D, Alleva E. Ultrasonic vocalisation emitted by infant rodents: A tool for assessment of neurobehavioural development. Behav Brain Res. 2001; 125: 49-56.

[95] Ehret G. Infant rodent ultrasounds - a gate to the understanding of sound communication. Behav Genet. 2005; 35: 19-29.

[96] Brudzynski SM, Kehoe P, Callahan M. Sonographic structure of isolation-induced ultrasonic calls of rat pups. Developmental psychobiology. 1999; 34: 195-204.

[97] Fujita E, Tanabe Y, Shiota A, et al. Ultrasonic vocalization impairment of Foxp2 (R552H) knockin mice related to speech-language disorder and abnormality of Purkinje cells. Proc Natl Acad Sci U S A. 2008; 105: 3117-3122.

[98] Groszer M, Keays DA, Deacon RM, et al. Impaired synaptic plasticity and motor learning in mice with a point mutation implicated in human speech deficits. Curr Biol. 2008; 18: 354-362.

[99] Gaub S, Groszer M, Fisher SE, Ehret G. The structure of innate vocalizations in Foxp2-deficient mouse pups. Genes Brain Behav. 2010; 9: 390-401.

[100] Bell RW, Nitschke W, Zachman TA. Ultra-sounds in three inbred strains of young mice. Behavioral biology. 1972; 7: 805-814.

[101] Roubertoux PL, Martin B, Le Roy I, et al. Vocalizations in newborn mice: genetic analysis. Behavior genetics. 1996; 26: $427-437$.

[102] Hahn ME, Schanz N. The effects of cold, rotation, and genotype on the production of ultrasonic calls in infant mice. Behavior genetics. 2002; 32: 267-273.

[103] Sugimoto H, Okabe S, Kato M, et al. A role for strain differences in waveforms of ultrasonic vocalizations during malefemale interaction. PloS one. 2011; 6: e22093.

[104] Kikusui T, Nakanishi K, Nakagawa R, Nagasawa M, Mogi K, 
Okanoya K. Cross fostering experiments suggest that mice songs are innate. PloS one. 2011; 6: e17721.

[105] Vernes SC, Oliver PL, Spiteri E, et al. Foxp2 regulates gene networks implicated in neurite outgrowth in the developing brain. PLoS genetics. 2011; 7: e1002145.

[106] Enard W, Gehre S, Hammerschmidt K, et al. A humanized version of Foxp2 affects cortico-basal ganglia circuits in mice. Cell. 2009; 137: 961-971.

[107] Haesler S, Wada K, Nshdejan A, et al. FoxP2 expression in avian vocal learners and non-learners. J Neurosci. 2004; 24: 3164-3175.

[108] Teramitsu I, White SA. FoxP2 regulation during undirected singing in adult songbirds. J Neurosci. 2006; 26: 7390-7394.

[109] Miller JE, Spiteri E, Condro MC, Dosumu-Johnson RT,
Geschwind DH, White SA. Birdsong decreases protein levels of FoxP2, a molecule required for human speech. J Neurophysiol. 2008; 100: 2015-2025.

[110] Haesler S, Rochefort C, Georgi B, Licznerski P, Osten P, Scharff $\mathrm{C}$. Incomplete and inaccurate vocal imitation after knockdown of FoxP2 in songbird basal ganglia nucleus Area X. PLoS biology. 2007; 5: e321.

[111] Schulz SB, Haesler S, Scharff C, Rochefort C. Knockdown of FoxP2 alters spine density in Area X of the zebra finch. Genes, brain, and behavior. 2010; 9: 732-740.

[112] Surmeli G, Akay T, Ippolito GC, Tucker PW, Jessell TM. Patterns of spinal sensory-motor connectivity prescribed by a dorsoventral positional template. Cell. 2011; 147: 653-665. 


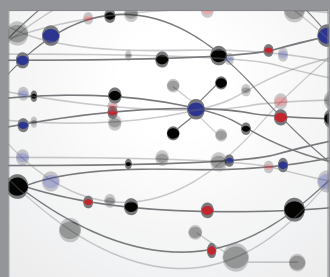

The Scientific World Journal
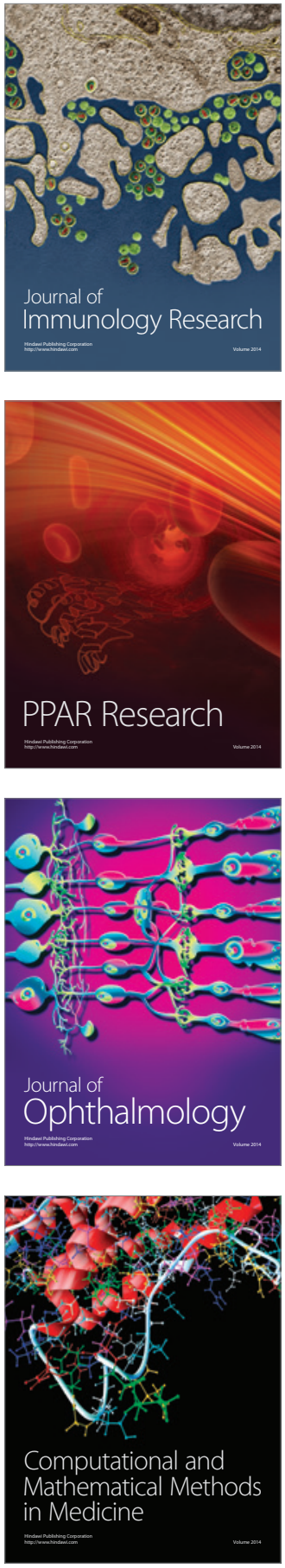

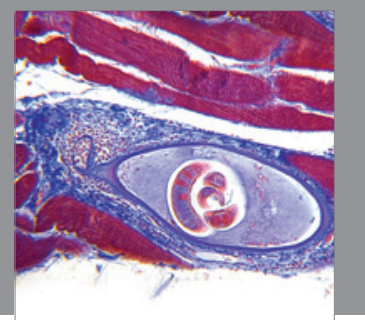

Gastroenterology

Research and Practice
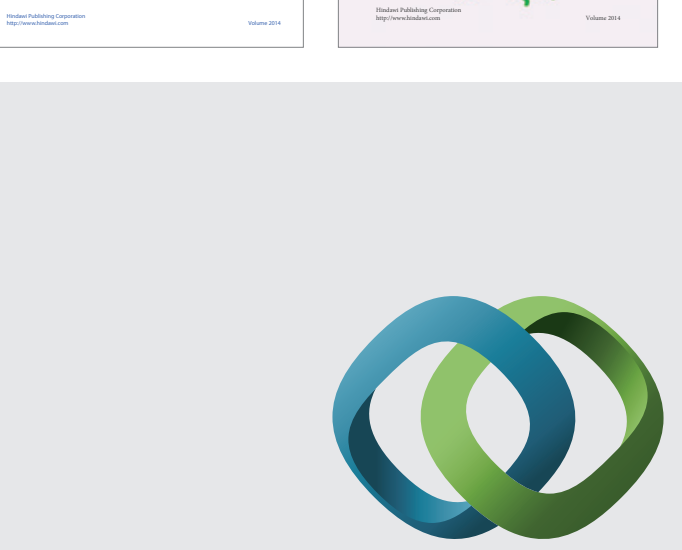

\section{Hindawi}

Submit your manuscripts at

http://www.hindawi.com
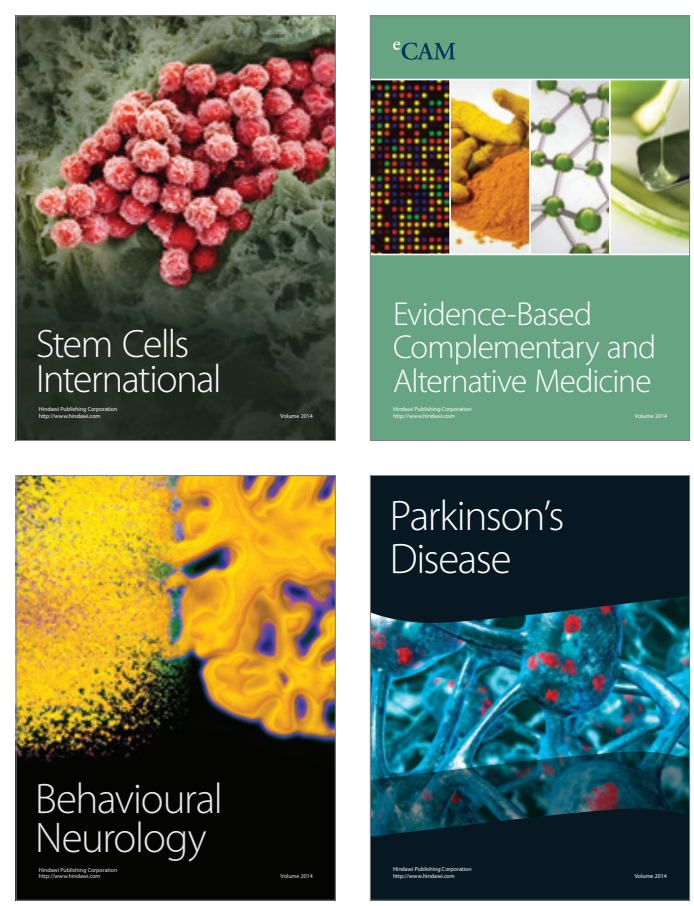

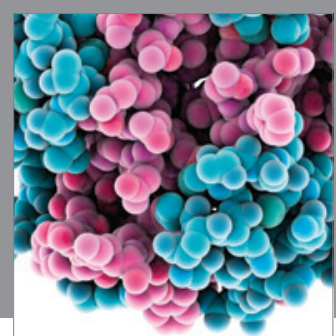

Journal of
Diabetes Research

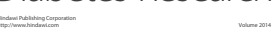

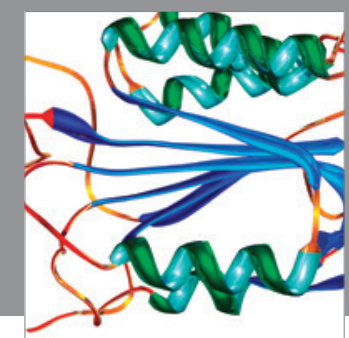

Disease Markers
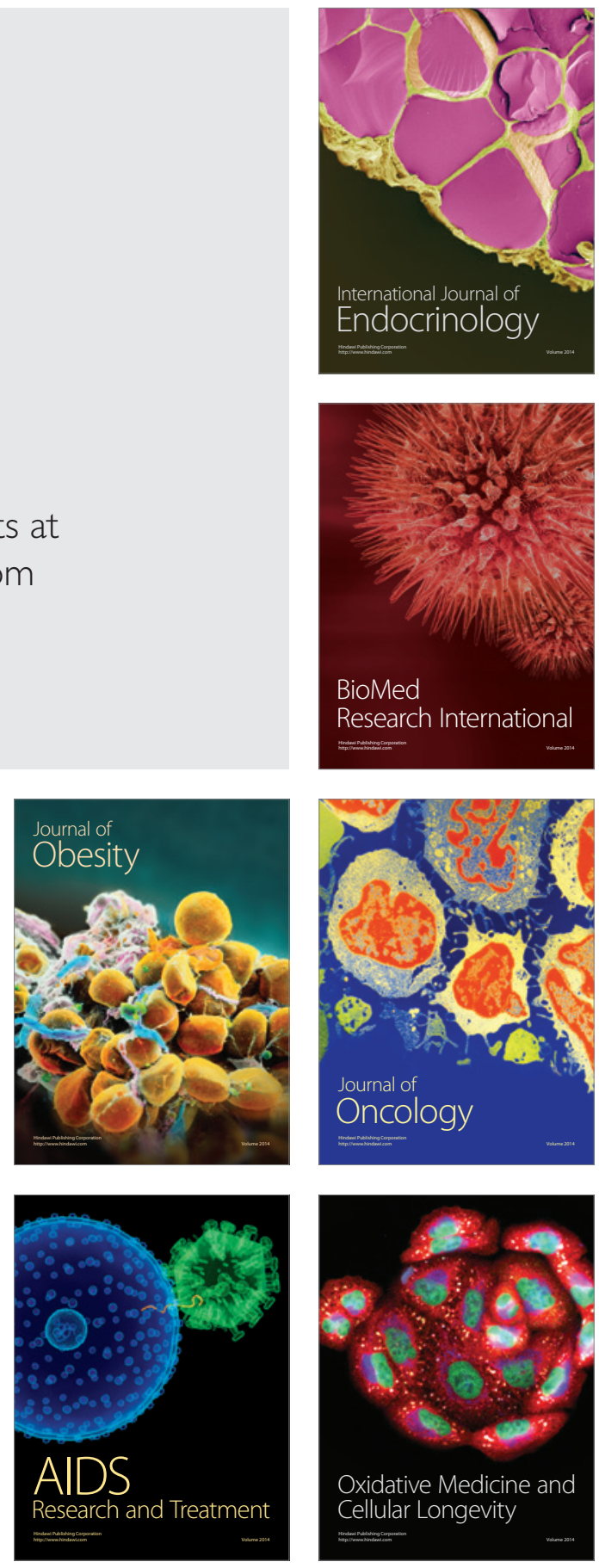